\title{
Voces femeninas
}

en la guerra de independencia

de Cuba: Lila

de Luáces y

Eva Adán de

Rodríguez

Jorge Camacho

Recebido em: 20 de setembro de 2019

Aceito em: 19 de dezembro de 2019
Jorge Camacho es Profesor Titular e investigador de Literatura Comparada, Español y Estudios Latinoamericanos en la University of South Carolina, Columbia. Es autor de 5 monografías y 8 volúmenes, todos con textos inéditos de José Martí, Rubén Darío y Mercedes Matamoros. Su último libro es La angustia de Eros: Sexualidad y violencia en la literatura cubana (Almenara, 2019).

Contato: camachoj@mailbox. sc.edu

Estados Unidos 
PALABRAS CLAVE:

mujeres; suerra;

independencia; Cuba;

Estados Unidos.

KEYWORDS: women; war; independence ${ }_{i} \mathrm{Cuba}_{i}$ United States.
Resumen: Durante la primera suerra de independencia de Cuba, que comenzó en 1868 y duró diez años, aparecieron en la isla y los Estados Unidos varias narraciones que hablaban del conflicto bélico. Una de estas narraciones fue escrita por Lila Waring de Luáces, una norteamericana casada con un cubano. En este ensayo discuto ese texto y lo comparo con otro, aparecido después de la guerra, escrito por otra sobreviviente en la isla. En ellos destaco las formas de representar la violencia y el Yo en estas narraciones, así como lo más importante: el archivo de hechos que van creando como contrapeso a la historia oficial del poder español en Cuba.

Abstract: During the first war of independence in Cuba, which started in 1868 and lasted ten years, a number of narrative texts appeared in Cuba and the United States detailing the conflict. One of these texts was written by an American: Lila Waring de Luáces, who was married to a Cuban. In this article I discuss this testimony and I compare it with another one published in Cuba after the war, also written by another female survivor. I discuss the way violence and the one's self is represented in these narrations, and most importantly how they build an archive of deeds to criticize Spain's official (hi)story of the Cuban conflict. 
A partir de la publicación en 1966 de Biografía de un Cimarrón de Miguel Barnet, numerosos ensayos han tratado de definir el género de testimonio en Latinoamérica. Un género llamado "sin arte” que tradicionalmente habla de intimidad y compromiso político, dándole voz a aquellos que no la tienen. Así el antiguo esclavo, la guerrillera o la mujer indígena ocuparon el lugar central de estas discusiones. No extrańa entonces que para John Beverley la característica principal del testimonio en Latinoamérica sea precisamente su marginalidad, su lugar descentrado, alejado de la metrópoli imperial como fue el caso del Inca Garcilaso de la Vega, o el cimarrón de Barnet. En particular, dice Beverley, el testimonio sirve de vehículo para sujetos como el nińo, la mujer, la indígena o el proletario, que han sido excluidos de las representaciones autorizadas "when it is a question of speaking and writing for themselves rather than being spoken" $(2004,93)$.

En este ensayo discutiré dos textos escritos por mujeres que pertenecían a la clase esclavista en Cuba. Las dos narran vivencias de finales del siglo XIX que tienen que ver con la guerra. Una de ellas era norteamericana y la otra, aunque nació en Cuba, adoptó la ciudadanía del mismo país cuando se exilió en los Estados Unidos. Una de estas narraciones está escrita en inglés, y fue traducida por José Martí. Sin embargo, hasta el presente se desconocía el original, ya que no se había podido localizar el periódico de donde la tomó el cubano. ${ }^{1} \mathrm{El}$

1 Para más detalles véase las Obras Completas. Edición crítica, vol. 21, donde a pie de la traducción de Martí en ese volumen los editores escriben: "No se ha podido hallar el texto en inglés. En el ángulo superior izquierdo: "De The Times./de New York" (436). 
otro testimonio de la guerra fue publicado en Cuba en 1935 y fue escrito por Eva Adán de Rodríguez.

Estos dos textos, además de ser escritos por mujeres, comparten otra característica fundamental: el servir de resistencia al poder colonial en la isla, ya que ambas participaron en el conflicto bélico del lado de los cubanos y su escritura era parte de una experiencia colectiva, no autorizada, que narra desde el punto de vista de la víctima los estragos y las injusticias que provocaron los enfrentamientos.

Desafortunadamente, ninguno de los nombres de estas mujeres ni sus testimonios han formado parte del canon o de las discusiones de la representación de la guerra. Sus nombres no aparecen en diccionarios ni en monografías de la isla o de los Estados Unidos, a pesar de que representan sus vivencias y son un ejemplo de los sacrificios por los que pasaron las cubanas a partir del momento en que los criollos le declararon la guerra a la metrópoli. Son recordatorios del sufrimiento que tuvieron que atravesar, la pérdida de vidas y la miseria en que vivieron miles de familias en los montes. Su escritura hay que verla como un "recordatorio" y una forma de construir un archivo de agravios. Por esta razón, en lo que sigue, me gustaría explicar con más detalles el contexto socio-histórico en que se originaron, su lugar de enunciación, y su relación con otros textos que también hablan del conflicto, pero que fueron escritos por hombres. Analizaré cómo el género informa su escritura y daré a conocer el texto perdido de Luáces.

Hojas de Recuerdos, de Eva Adán de Rodríguez, se publicó en 1935 con una introducción de Dr. Gonzalo Aróstegui, y un epílogo del periodista Miguel 
de Marcos (1894-1954) quien, por la casualidad, vivía en un apartamento ubicado debajo del de Eva Adán en La Habana, y le pidió que escribiera sus memorias después de saber que había conocido algunos de los héroes más famosos del alzamiento. Eva Adán estaba casada además con Alejandro Rodríguez Velazco (1852-1915), quien fue general de división del Ejército Libertador durante la guerra de 1868 y después del triunfo republicano se convirtió en el primer alcalde de La Habana. Su cercanía al poder anticolonial por tanto era importante, igual que lo fue para Eliza H. Waring de Luáces, quien se casó con el coronel del Ejército Libertador, y también médico, Emilio Lorenzo Luáces (1842-1910). Las dos mujeres vivían en la provincia de Camagüey al inicio de la contienda y tenían una posición privilegiada al menos hasta que comenzaron las hostilidades y tuvieron que escapar a los Estados Unidos.

Eliza Waring y Lorenzo Luáces se conocieron y se casaron en Nueva York en 1863. Lorenzo y su hermano, Antonio, habían ido a los Estados Unidos a estudiar Medicina y durante la Guerra de Secesión en los Estados Unidos (1861-1865), Antonio se enroló en el Ejército del Norte donde llegó a obtener los grados de coronel. Más tarde, Antonio se incorporó al Ejército Libertador en Cuba, hasta que fue tomado prisionero en 1875 y juzgado a muerte en consejo de guerra por los españoles. Después de contraer matrimonio en los Estados Unidos, Lorenzo y Eliza Waring se fueron a vivir a Cuba, donde la familia Luáces tenía uno de los ingenios más importantes de Camagüey, El Oriente, famoso por su belleza y su importancia en la región.

Tal es así que el cura español Antonio Perpiñá habla de El Oriente en su libro El Camagüey, viajes pintorescos por el interior de Cuba y por sus costas 
(1889), y resalta su belleza y el buen trato de su dueño. De acuerdo con Perpiñá, El Oriente tenía alrededor de 200 esclavos africanos cuando lo visitó en la década de 1860. Tenía el estilo de un chalet suizo e iluminado por las noches con lámparas chinas parecía una casa de hadas $(1889,88)$. Al comienzo de la guerra, no obstante, El Oriente se convirtió en un lugar de reunión para jefes revolucionarios como Ignacio Agramonte (1841-1873) y el General Donato Mármol (1843-1870), y por eso, poco después Liza Waring y su esposo tuvieron que abandonar su propiedad, y se unieron a las tropas independentistas en la manigua: Lorenzo en calidad de médico y Liza sirviendo de enfermera en los hospitales de sangre que se construían en el monte.

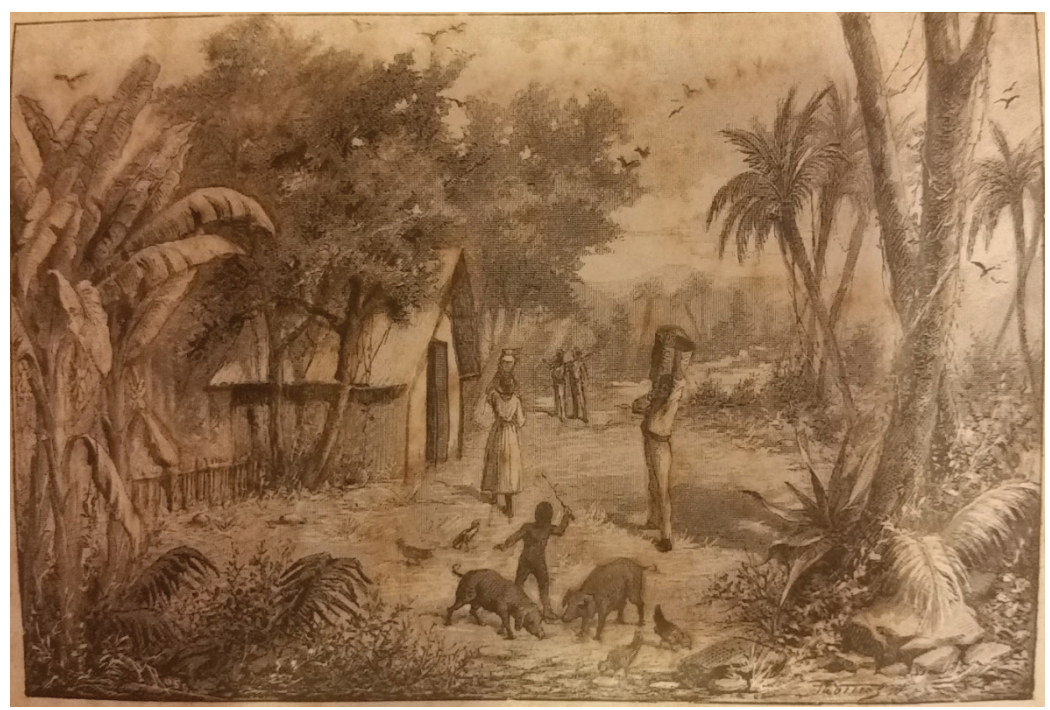

Figura 1 - Conuco y bohío de los negros esclavos en el ingenio El Oriente, propiedad de la familia Luáces. Fuente: El Camagüey, viajes pintorescos por el interior de Cuba y por sus costas (1889), de Antonio Perpiñá. 
Por esta razón, tanto Liza Waring como Eva Adán de Rodríguez proveerán al lector de una perspectiva muy diferente a la que brindan los textos que fueron producidos por hombres y que lucharon en la guerra. No nos hablan de su participación en los combates porque las mujeres en su inmensa mayoría no participaban en los conflictos bélicos, sino que permanecían en los ranchos cerca de los campamentos curando los heridos, remendando sus ropas y apoyando a sus maridos. Su posición, condicionada por el género, nos da una visión de la guerra que se origina desde los lados, desde la retaguardia o los espacios liberados u ocultos adonde no habían llegado todavía las tropas peninsulares, lo cual no quiere decir que escaparan de las represalias o no sufrieran castigo si eran halladas en estos hospitales y se les consideraba enemigas de Espańa. Por eso, como dejan explícito los textos de estas mujeres, cualquier civil que simpatizara con los mambises podía ser juzgado y en más de una ocasión, Liza Waring narra cómo familias enteras fueron asesinadas por una simple sospecha.

En el caso del testimonio de Eva Adán de Rodríguez, su condición social pasa incluso a ocupar un primer plano ya que repetidas veces contrasta su vida en la manigua y su vida antes en Puerto Príncipe, la ciudad principal de Camagüey, donde su familia vivía antes de estallar la guerra. Como afirma casi al inicio del texto, su familia tuvo que dejar la ciudad tan pronto los soldados españoles instalaron cañones en las torres del templo de la Merced en Puerto Príncipe, para proteger la ciudad de los ataques de los rebeldes. El templo estaba al lado de su casa. En aquellos momentos, Eva Adán era todavía una adolescente, y dado la fortuna de sus padres, estos pensaban 
enviarla a estudiar a Florencia, Italia. En cambio, toda la familia tuvo que abandonar la ciudad y refugiarse en su finca, la cual pronto tuvieron que abandonar también y trasladarse a una choza en el monte.

Por consiguiente, la narración de Eva Adán está marcada por un "antes y un después" que ilustra el cambio identitario por el que pasaron los protagonistas de estas narraciones, y coincide con la forma en que los criollos independentistas se vieron a sí mismos después de estallar el conflicto. "Antes" vivían una vida llena de confort y "después" no les quedó otro remedio que sobrevivir en la pobreza y el hambre, pero motivados por el amor a la patria. Este discurso será el que mantendrá la reserva de patriotismo en obras de teatro como "El grito de Yara", de Luis García Pérez, y novelas proindependentistas como Vía crucis, de Emilio Bacardí (Camacho, 2018, 51-52). En estas narraciones, las mujeres abandonan también sus hogares y se marchan a la manigua con sus esposos o sufren una vida de miseria en la ciudad.

Como apunta Eva Adán en su narración, el propio Máximo Gómez, jefe del Ejército Libertador, le había dicho una vez que era una "aristócrata", alguien que había gozado antes de la guerra de un estatus social mucho más alto que la mayoría de los hombres y mujeres que lucharon a su lado. Pero ese estatus, como vemos en el libro, rápidamente cambia cuando su familia se ve obligada a huir al monte y los espańoles confiscan sus propiedades por simpatizar con los rebeldes. De modo que, de acuerdo con un comentario irónico que le hizo su hermana en el lugar donde se encontraban ocultas, cuando vivían en la "opulencia" usaban agujas ordinarias, "y hoy que carecemos de todo, las tenemos de oro" $(1935,60)$. La ironía en el comentario de 
la hermana residía en el hecho de que en la manigua, por no tener ninguno de los utensilios que tenían en la ciudad, tenían que ser creativas y usar cualquier objeto para ayudarse, por eso utilizaban sus broches de oro para remendar sus ropas. En su narración por consiguiente estamos en presencia de un doble desplazamiento: el sujeto ocupa un lugar que no le corresponde al cambiar su vida por la de una persona común. Asimismo, los objetos que usa de la otra vida sirven para hacer algo más para lo cual no estaban diseñados originalmente. En ambos casos el movimiento se inscribe como una contradicción con el lugar, como una especie de anatopismo (del prefijo ana-, que significa contra, y topos que significa lugar) en que el sujeto y sus objetos aparecen desplazados, sin el prestigio, el dinero o la función que ocupaban en la vida anterior. En todo caso, la visión se origina desde un espacio marcado por la clase social que pierde en importancia material al mismo tiempo que suple esa disminución con el patriotismo.

Así, en la narración de Eva Adán sobresalen los recuerdos personales, las memorias de su familia en las fincas y chozas del monte donde se refugiaron y en estos recuerdos siempre está presente la idea que su lugar está en otra parte, que su vida es otra y que hasta las ropas que lleva puestas no son las que debería tener. De esta forma, sus recuerdos funcionan como lugares distópicos, en que se mezclan su identidad aristocrática y su vocación de patriota. Uno de estos recuerdos aparece cuando rememora que después que los españoles habían asaltado su casa y roto todos los muebles lo que más le angustió fue encontrar los espejos rotos "porque deseaba conocerme transformada de niña en mujer" $(1935,34)$. La falta de espejos hacía imposible que se reconociera. Un año 
después, cuando las tropas españolas finalmente las toman prisioneras y las transportan a la ciudad con sus padres, Eva Adán logra verse en un espejo y dice:

Imposible describir la impresión y el malestar que experimenté al contemplarme de cuerpo entero en aquellos grandes espejos, jtan pobre y ridículamente vestida!... //Como era una niña cuando salí al campo y en se tiempo había crecido y desarrollado más, no tenía ropa que me sirviera y la incomunicación con los pueblos impedía abastecernos con lo más necesario, se habían aprovechado para mis trajes aquellas colchas de saraza de vivos colores que se usaban en el campo para camas y cortinas, cuyos dibujos eran flores, pájaros, frutas, etc. etc. La pinta del que yo llevaba ese día era de berenjenas; los zapatos hechos en la manigua con piel de jutia, sin figura ni tamaño $(1935,40-41)$.

Por consiguiente, como en el caso anterior en que Eva Adán habla de las dificultades que tenían para encontrar agujas en el campo, aquí reconstruye sus memorias a partir del contraste que producían las ropas hechas con retazos de telas que entonces solo se usaban para cortinas y camas. De esta visión surge la inconformidad, la visión "ridícula" que juzga su apariencia por los valores aristocráticos que aprendió de niña antes de huir. El mismo gesto aparece cuando Eva Adán ve entre los mambises que llega a su casa Félix Aguirre, harapiento, vestido con ropas que le habían hecho de un viejo forro de catre y desde el primer momento se fija "en unos preciosos botones de nácar que se destacaban en aquel sucio y raído uniforme” $(1935,57)$. Una y otra vez, por tanto, la mirada de la adolescente se fija en el contrate que se establece entre dos objetos encontrados en el mismo lugar, que chocaban entre sí por su origen o su valor. En otras palabras, son objetos que estaban en el lugar que no les pertenecía, igual que estaba ella en el monte rodeada 
de malezas y objetos en desuso. No extraña entonces que para un sujeto poco acostumbrado a sobrevivir en la manigua todo lo que pudiera hacerse con objetos y partes de animales que no fueran las acostumbradas, causara asombro. Según Eva Adán en aquellos momentos:

La necesidad aguzaba las ideas y despertaba las habilidades; se rehacían los cepillos de dientes con crines de caballos, de los rabos de las jutías se hacían dedales; y Lecondia, una de mis hermanas conservaba uno que era una perfección. Al faltarles agujas, utilizaba los alfileres de sus prendedores de oro. $(1935,59)$

La narración de Eva Adán regresa por tanto una y otra vez sobre la experiencia del "Yo" que tiene que abandonar su lugar de origen, sus costumbres y adaptarse a otra vida, ya sea en el monte o en el exilio. Ese cambio la obliga a vestirse diferente y aprender habilidades que no eran propias de su época como curar a los heridos o dedicarse a confeccionar cartuchos para las armas que utilizaban los independentistas. Por eso, afirma que a pesar de que a las niñas de su tiempo se les enseñaba a coser y hacer bordados, nunca aprendió "las labores propias de mi edad y condición”, esto es, a bordar, coser y tejer $(1935,65)$.

En el caso de la narración de Eliza Waring las marcas sociales son menos evidentes. Sobre todo, porque "Lila", que era como la llamaban sus amigos y como firma en el periódico norteamericano, no habla de su vida íntima como lo hace Eva Adán. Su texto habla de la guerra y de los crímenes con un conocimiento vivencial que Rodríguez no tiene. Habla con más emoción y ansiedad de lo ocurrido, tal vez porque a diferencia de Eva Adán, Lila escribe 
su narración en el mismo momento en que sucedía la guerra, no treinta y dos años después de lograda la independencia. Además, Liza, a diferencia de Eva Adán, era ya una mujer adulta en el momento en que estalla el conflicto. Tuvo que tomar decisiones por ella misma y huir con su esposo a la manigua. En tal sentido, su memoria es un testimonio contrario a la violencia de los soldados españoles contra los civiles y un recordatorio constante de la posibilidad de ser sorprendidos en la manigua a cualquier hora del día por ellos. En su caso, además, la narración se publicó en varios periódicos estadounidenses mientras acontecía la guerra, y por eso su testimonio se convirtió en un arma de lucha y en un alegato contra el gobierno español.

En efecto, una vez que logra escapar de Cuba y llegar a los Estados Unidos, Lila dio a la imprenta una carta con el título "Extraordinary narrative of Mrs. Lila Waring de Luáces” en cuya introducción los editores la califican como una prueba del trato inhumano que daban las autoridades españolas a los cubanos en la isla y subrayan además su capacidad de testigo al afirmar que residía en Cuba cuando estalló la guerra y que junto con su esposo estuvo a cargo por dos años de los hospitales de los insurgentes.

Así, de acuerdo con el editor del New York Tribune, Lila logró llegar a los Estados Unidos en 1870, dos años después de comenzar la guerra, pero se había refrenado de publicar esta carta, dado la posible repercusión que podía tener en su esposo que todavía permanecía en Cuba. De todas formas, el periódico publica esta carta en la cual Eliza Waring describe con detalle las “atrocidades" que cometían los soldados españoles en Cuba, especialmente contra los civiles que creían que simpatizaban con los rebeldes. 
Voces femeninas en la guerra de independencia de Cuba: Lila de Luáces y Eva Adán de Rodríguez

Jorge Camacho

NEW-YORK DAILY TRIBUNR, SATURDAY.

A

\section{ATROCIFIES IN OUBA.}

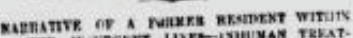

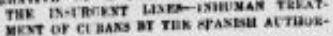
Mikst

IThe following acement of the treafment of

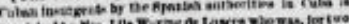

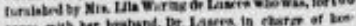

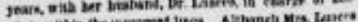

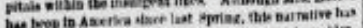

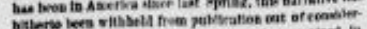

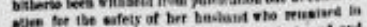

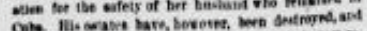

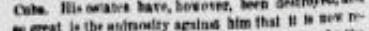

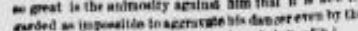

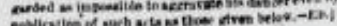

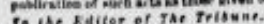

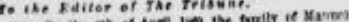

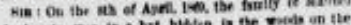

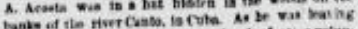

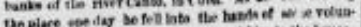

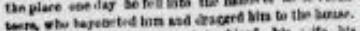

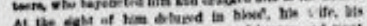

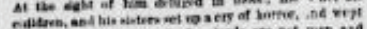

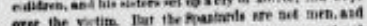

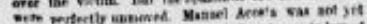

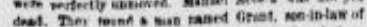

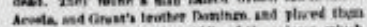

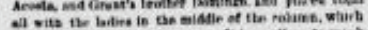

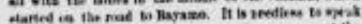
at the tratarse of the pritedere on the vay, bor of the

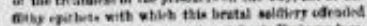

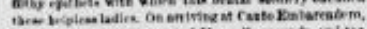

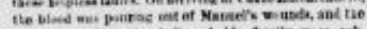

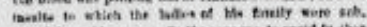

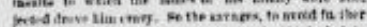

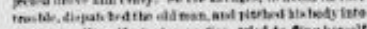

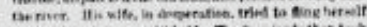

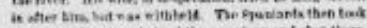

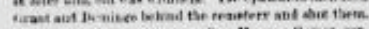

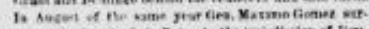

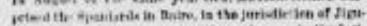

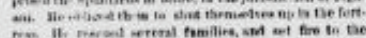

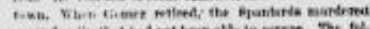

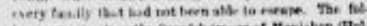

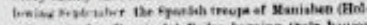

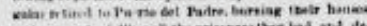

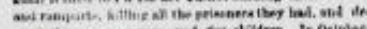

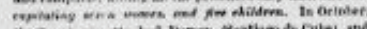

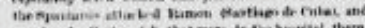

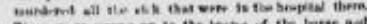

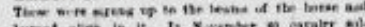

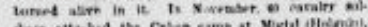

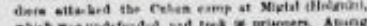

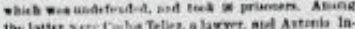

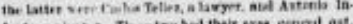

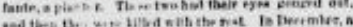

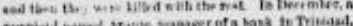

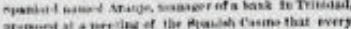

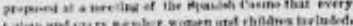

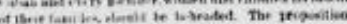
*.t sileptict sich mrat aigherer

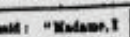

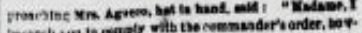

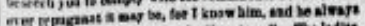

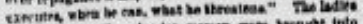

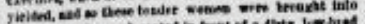

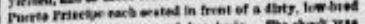

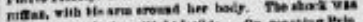

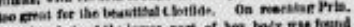

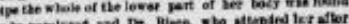

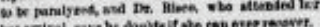

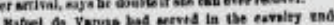

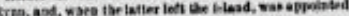

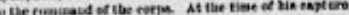

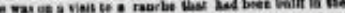

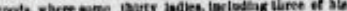

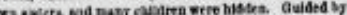

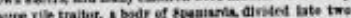

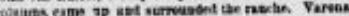

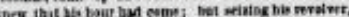

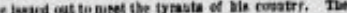

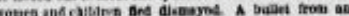

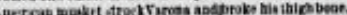

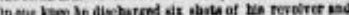
Cut

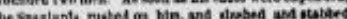

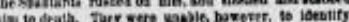

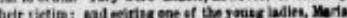

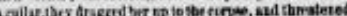

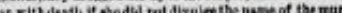
a

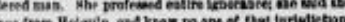

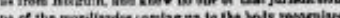
Tion

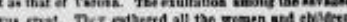

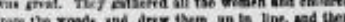

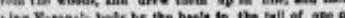

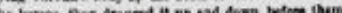

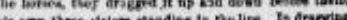

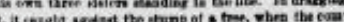

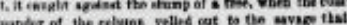

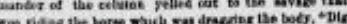

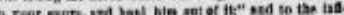

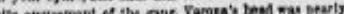

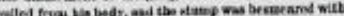
bisebraine

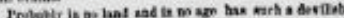

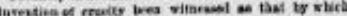

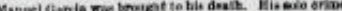

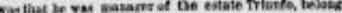

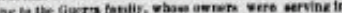

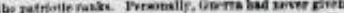

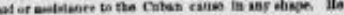

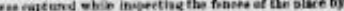

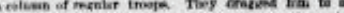

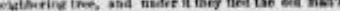

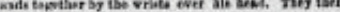

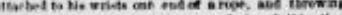

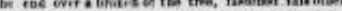
ad to s viabs is Be promad. Fley provisaly litied an

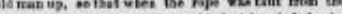

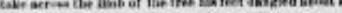

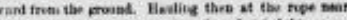

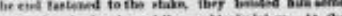

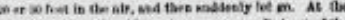

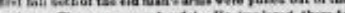

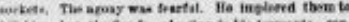

Figura 2 - New York Tribune.

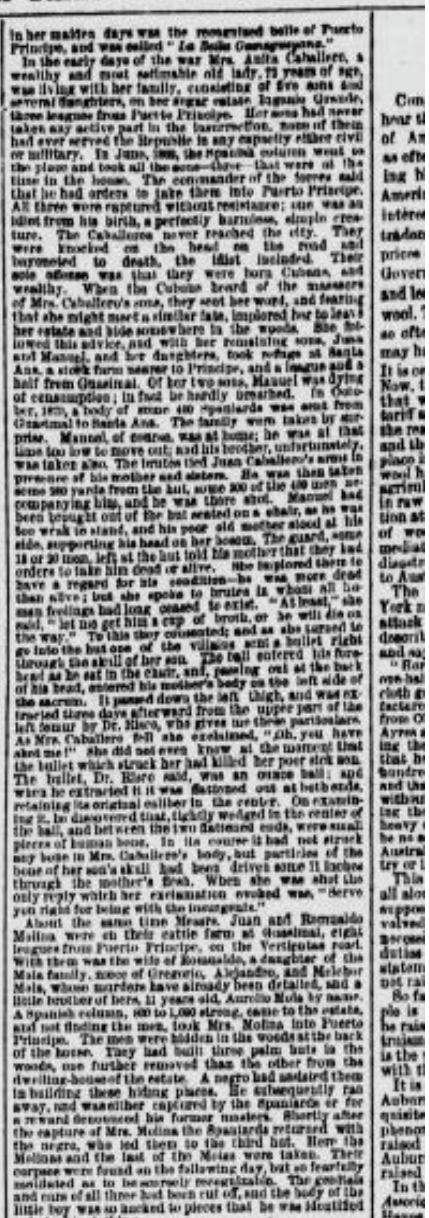

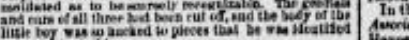

En su carta-testimonio, Luáces habla de mujeres y hombres que son asesinados sin excusa y de cuerpos que son despedazados, desmembrados 
y quemados vivos como ocurre con las mujeres, los hombres y los niños de las familias De Mola y Molina. Los hombres de estas familias, dice Luáces, fueron apresados y encontrados más tarde tan ferozmente mutilados que fue difícil reconocer sus cuerpos. "Los genitales y las orejas de los tres habían sido cortados y el cuerpo del pequeńo nińo había sido tan macheteado a pedazos que solamente pudo ser identificado por su ropa" $(1871,4)$. La violencia de la letra en este testimonio era un reflejo de la lucha desigual y asimétrica que ocurría en la isla. Busca crear empatía en el lector recurriendo a la narración de casos extremos como el de la familia De Mola, cuya muerte aconteció después de que Lila había abandonado Cuba, pero aun así logra insertarla en su texto.

Por eso es importante señalar que a pesar de que Lila de Luáces vivió en Cuba durante la guerra, y estuvo casada con uno de los principales jefes en Camagüey, no todo lo que cuenta en su carta fueron acontecimientos que ella misma vio. Es decir, no siempre habla con la voz del testigo. De hecho, Luáces tampoco reclama la posición de observador o de víctima. Su testimonio toma la forma de un recuento de crueldades que los espańoles cometen contra los cubanos. Incluso, sabemos que Lila habla de algo que conoció de forma directa por la introducción al artículo que escribió el editor del New York Tribune, de lo contrario no hubiéramos sabido del lugar central que ocupa en la guerra.

Podríamos preguntarnos entonces ¿Por qué Lila de Luáces no habla de ella misma en esta narración? ¿Por qué deja fuera los detalles personales? Posiblemente, podríamos respondernos, para poner todo el énfasis en los que 
sí sufrieron directamente la violencia, con lo cual su narración se enfocaría en los hechos, y dejaría fuera lo subjetivo, el Yo que escribe esta narración. En tal sentido, estamos en presencia de un texto muy diferente al de Evan Adán, donde el Yo ocupa el primer plano. Por eso, Lila recurre a un lenguaje expositivo, se enfoca más en el "dónde", “cómo” y "cuándo" que en el “yo" que, como sugiere Georg Misch en History of Autobiography in Antiquity, está en el centro de toda autobiografía (80). Su vida y cualquier trauma personal por el que pasó, parece decirnos, no es el tema de esta narración. Después de todo, Lila pudo escapar de la isla y regresar a los Estados Unidos, algo que no pudieron hacer muchas familias cubanas que no tenían su dinero, ni la ciudadanía que les permitía la protección de su país. Su único interés son las víctimas del conflicto que en su mayoría son inocentes, mujeres y niños con lo cual se demuestra todo el horror de la guerra. Podríamos decir entonces que al igual que otras narraciones famosas que deja la violencia al descubierto, como la del Padre Bartolomé de las Casas en La Brevísima relación de la destrucción de las Indias (1552), la de Lila de Luáces reproduce un discurso factual, demostrativo, acusador, que se apoya en otras voces ajenas para defender a las víctimas. En el caso de Las Casas, los indígenas, y en el caso de Lila de Luáces, los cubanos. No es extraño entonces que ese estilo directo, tan similar a como lo hiciera un fiscal ante un juez, recurra a datos precisos, dé el nombre de las víctimas, el día y la hora exacta en que fueron asesinadas. Así, Lila comienza su carta al editor del New York Tribune con la siguiente frase: "On the 8th of April, 1869, the family of Manuel A. Acosta was in a hut hidden in the woods on the banks of the 
river Cauto in Cuba" cuando los soldados espańoles llegaron y mataron a todos los hombres $(1871,4)$.

Su estilo es conciso y directo. Le provee al lector con datos específicos de cómo sucedieron estos crímenes e intenta no inmiscuir un punto de vista ajeno a la narración, dejando afuera todo aquello que no era necesario como las descripciones del paisaje o los elementos poéticos que podrían darle belleza al texto. De este modo, con estos elementos Lila escribe una contra-memoria, en el sentido que Michel Foucault le da a este concepto, que se opondría a las historias tradicionales y, en este caso, a cualquier historia que podían escribir los espańoles (153-54). Con estas memorias en la mano, Lila como todos los revolucionarios intenta preservar un tipo especial de conocimiento, como diría Bruce James Smith en Politics \& Remembrance, "the knowledge of the free people" $(1985,21)$.

De esta forma, su narración, al igual que las obras de teatro y poemas que publicaron los independentistas durante la guerra, sirve para engrosar las causas por las cuales los cubanos se alzaban en armas. Pertenecen al archivo anticolonial con el cual los revolucionarios podían reclamar también la simpatía de los norteamericanos: el país del cual esperaban el reconocimiento de la beligerancia e incluso la posibilidad de anexión para escapar de España. ${ }^{2}$ Esta función del testimonio como archivo, por tanto, se refuerza en el texto cuando Luáces menciona las cartas que recibió de las víctimas y los testimonios que escuchó de sus labios, detallando algunas de estas

2 Para una discusión más amplia sobre la importancia del archivo en las culturas occidentales véase lo que dice Aleida Assmann en Cultural Memory and Western Civilization. 
crueldades. Son cartas que, como dice, habían mandado al departamento de la guerra donde estaban los rebeldes junto con ella y su esposo.

Dos de las cartas que cita fueron escritas por Narciso Tamayo, vecino de Sierra Maestra, en el Oriente de Cuba, y Salvador Cuevas, de la provincia de Villa Clara, en los meses de abril y enero de 1870. Luáces reproduce ambas cartas en su texto lo cual muestra el interés en dejar que hable el otro y hacer ver la violencia de forma directa $(1871,4)$. Consciente, entonces, del poder del archivo, de la letra impresa y del testimonio de la víctima, Luáces traduce y transcribe estas misivas, agrega comentarios e información que refuerzan el mensaje, por lo cual su testimonio funciona sobre una bolsa que guarda en su interior otras voces que no son las suyas, otros testimonios a través de los cuales puede decir la verdad, ya que son una prueba directa del conflicto, calificando las acciones de los soldados de "atrocidades" y a los españoles de "salvajes" $(1871,4)$.

Con esto quiero decir que al publicar este testimonio en la prensa estadounidense, la joven norteamericana no solo buscaba solidarizar al público con la causa de los criollos, sino que también construyó una subjetividad muy diferente, inclusiva, transnacional y distinta a la de otras mujeres en la época, que no escribían en los diarios, y mucho menos participaban en el conflicto. De hecho, uno de los elementos más importantes de la guerra de Cuba es la construcción del género femenino de una forma radicalmente diferente a como se pensaba antes de 1868, ya que según la cultura patriarcal de la época, las mujeres debían permanecer en sus casas, cuidar a sus hijos y al esposo. No se suponía que sostuvieran ideas políticas, y mucho menos que 
las defendieran en los campos de batalla. De ahí que los textos de la guerra que hablan de las mujeres se diferencien tanto cuando se trata de reflejar sus acciones, ya que para los espańoles las mujeres que se unían a los mambises en los montes eran promiscuas e indecentes, y los revolucionarios que se lo permitían eran tildados de ladrones, borrachos e inmorales. Los periódicos satíricos de la época como El Moro Muza y Don Junípero las increpaban todo el tiempo, con rimas que hacían énfasis en su inmoralidad. Así el primero decía de las mujeres que se alzaban con los maridos en el monte en 1869:

Los que hoy libertad proclaman

Son bien libertinos seres,

A juzgar por las mujeres

Que su ardor bélico inflaman.

Las señoras se llaman.

Es ya pública opinión,

Que, con gran satisfacción,

En cueros van tentadoras,

Y si eso hacen las señoras,

¿Qué harán los que no lo son? $(1869,64)$

En otra de las caricaturas que le hiciera el mismo periódico pro-español al principal líder del movimiento revolucionario, Carlos Manuel de Céspedes, este aparece con dos mujeres del brazo y dos niños a cada lado. La caricatura se titula "Céspedes inmoral y bígamo" $(1870,301)$ y aducía posiblemente al hecho de que, a pesar de estar casado, Céspedes tenía relaciones sexuales con otra mujer del lugar. ${ }^{3}$ En realidad muchos mambises lo hicieron, y esto era

3 Para un comentario sobre las relaciones extramatrimoniales de Carlos Manuel de Céspedes, considerado el Padre de la Patria en Cuba, véase el libro de Abel Sierra Madero Del otro lado del espejo: La sexualidad en la construcción de la nación cubana, especialmente las páginas 64-65. 
Voces femeninas en la guerra de independencia de Cuba: Lila de Luáces y Eva Adán de Rodríguez

una forma de atacarlos en los periódicos y rebajar su condición moral ante la vista de los lectores. Por eso, la acusación contra Céspedes se extendía a todos los hombres y mujeres que participaron en la guerra del lado de los revolucionarios, por lo cual al defender a los cubanos y descubrir el editor que ella también vivió en el monte junto con ellos, Luáces iba en contra de esa narrativa que las demonizaba y las convertía en seres execrables.

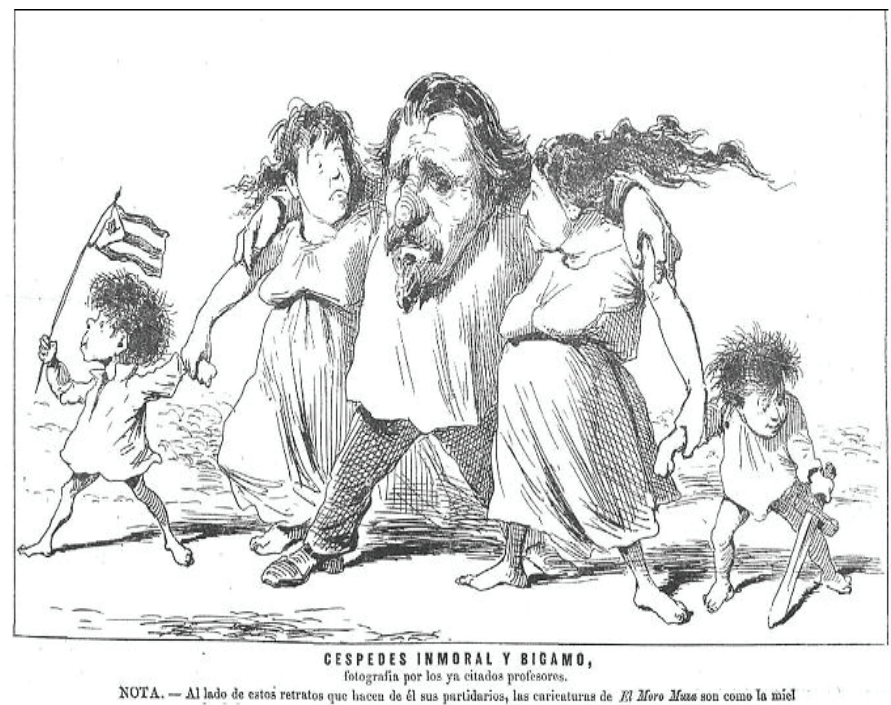

Figura 3

No es extraño entonces que Luáces termine su testimonio señalando la violencia de los españoles contra las mujeres que ayudaban a los mambises y que citara un caso en particular: el de la hija de los Morels, a la que ordenaron desnudarse delante de los oficiales españoles. Si la retórica de la guerra en 
contra de los revolucionarios construía mujeres "indecentes", el testimonio de Lila de Luáces dejaba al descubierto que eran las mismas autoridades españolas las que abusaban de su poder, las que tenían en menos a las cubanas y las que usaban esta estrategia para autorizar la violencia contra ellas.

Sin embargo, el caso de violencia más extrema que narra la joven norteamericana y que ocupa el centro de su narración es la historia de la familia De Mola, que fue asaltada y asesinada casi en su totalidad el 6 de enero de 1871. Para aquel entonces, Luáces ya estaba en los Estados Unidos y aun así logró recoger esta anécdota en su carta gracias a que consiguió hablar, dice, con el único sobreviviente de la matanza, el niño Melchor Loret de Mola.

El asesinato de la familia De Mola había ocurrido ese año en la misma provincia de Camagüey, donde residín los Luáces y la familia de Eva Adán, y tan pronto como sucedió se acusó al ejército español y en particular al destacamento de Acosta por el crimen. Según cuenta el propio Melchor de Mola años después, Acosta defendió su inocencia y el gobierno español conspiró para no aplicarle un castigo a los soldados. Por tanto, la historia que cuenta Lila de Luáces en su carta era verdadera y fue uno de los hechos de sangre más importantes y traumáticos del conflicto que duró diez años, y junto con el fusilamiento de los estudiantes de Medicina ese mismo año, galvanizó la opinión popular de los cubanos en contra de los peninsulares. Según Lila, ella tuvo conocimiento del caso por el mismo nińo: "it is taken from the lips of the little son of Mercedes whom the Spaniards had left for dead" (se tomó de los labios del pequeño niño de Mercedes a quienes los españoles habían dejado por muerto" traducción nuestra) $(1871,4)$. El 
hecho no terminaría tampoco allí, ya que años después, en 1893, el propio Melchor escribirá su testimonio de lo que sucedió esa noche en el rancho de su familia en Episodio de la Guerra de Cuba: El 6 de enero de 1871 (1893). Coincidentemente, dos años después de publicarse este libro, volvió a estallar la guerra, esta vez dirigida y organizada por José Martí en los Estados Unidos, y después de triunfar los republicanos, el único testigo de la matanza se suicidó. ¿Cómo describe entonces este acontecimiento Luáces en su carta?

Luáces se enfoca nuevamente en la violencia contra las mujeres, inocentes, que un día son asaltadas por dos soldados espańoles en su rancho que recorrían las cercanías del lugar en busca de revolucionarios. Al encontrarlas solas con sus hijos, exigen que les den su dinero y dada la negativa de las mujeres a entregárselo, estos machetean a todos y le preden candela a la casa. Vale citar in extenso esta parte del pasaje. Dice Lila, en la carta traducida por Martí:

Mientras tanto, otro de los malvados había tendido a Juana en el suelo.-Y entonces, excitados como los tigres por el aroma de la sangre, no hubo más que demonios que asesinaban y ángeles e inocentes que morían.-Un golpe que le dividió la cabeza arrojó a Mercedes a tierra, y allí, luchando en su desesperada agonía, fue como tantos han sido, rabiosamente despedazada. Montón informe, masa sanguinolenta fue hallado su mísero cadáver.-El pobre nińo se envolvió con los pedazos de la que fue madre adorada suya, y la ceguedad de los chacales les hizo ver en el niño herido otro nuevo cadáver.-Juana murió con toda la terrible rapidez que Mercedes había muerto.-Y aquellas furias destrozaron los cuerpos de cuatro niños más.-Y cuando al día siguiente, consiguieron encontrar seis cadáveres,_-faltaba en ellos la cabeza de una niña de cuatro años- ¡trofeo quizás de la heroicidad de aquellas hienas!—;Oh! pero aquellos españoles habían adivinado la manera de ser más que tigre feroz, más que hiena aun.- Habían adivinado que se podía prender fuego a una choza donde hubiese una nińa viva de dos años.-Y prendieron fuego, $-\mathrm{y}$ celebraban con carcajadas los lamentos 
de muerte del ángel—y la niña se quemó.— ¡Oh!-Se quemó.-El niño que me cuenta esto, dice y lo dice siempre: // -Mi hermanita estaba vivita quemada $(2008,446)$.

Me interesa subrayar aquí varios aspectos. El primero es la forma en que aparece reflejada la violencia de los soldados contra las mujeres y los niños indefensos, ya que fue un rasgo característico de las narraciones de los cubanos llamar la atención sobre este tipo de comportamiento por parte de los españoles y las guerrillas que los apoyaban. Tanto en la narración de Melchor de Mola como en la de Lila no hay respeto ni caridad por las víctimas. Los soldados ni siquiera están movidos por un ideal patriótico, sino que solo les interesa el dinero que tienen las familias criollas ricas que habían huido al monte con lo poco que les quedaba. De esto se deriva que si las cubanas morían por un ideal alto y patriótico, los españoles mataban por conseguir riqueza, y no importaba que tuvieran que robar y matar para lograrlo.

Más importante aún es notar en el fragmento citado que aquí, como en ningún otro lugar de la carta, aparece muy claramente el lenguaje literario como soporte de la narración. En este fragmento, los españoles se convierten en animales, en fieras sangrientas más motivados por el instinto que por su capacidad racional o emocional. Son "tigres", "hienas" y "chacales" excitados por "el aroma de la sangre" mientras que los niños son "ángeles", cuyos cuerpos estos hombres-animales destrozan "rabiosamente." Estas metáforas ordenan pues el texto, y se unen a otro tropo literario, la ironía, ya que en medio de su descripción de la misma escena, el hablante afirma 
que la cabeza de la niña de cuatro años había servido de “¡trofeo quizás de la heroicidad de aquellas hienas!”.

Claro está: la heroicidad y el crimen son conceptos antagónicos que no pueden reconciliarse, al menos que entendamos que el hablante las utiliza para resaltar la idea de la violencia extrema que se había cometido, y el gusto con que los soldados lo hicieron. Al hacerlo, el hablante deja implícito que es imposible recompensar con un galardón una acción de este tipo, y que solamente para personas que habían perdido su humanidad era posible ver en ello un honor. En ambos casos, por tanto, la literatura se convierte en un vehículo que amplifica las acciones, le agrega un sentido moral, las juzga desde una posición que ya no es la del discurso fáctico, literal y certero y nos permite definir un "ellos" contra un "nosotros" que sirve de base legitimante al discurso patriótico y nacionalista en ambos extremos.

Aclaro ahora que he citado la narración de Lila Waring de Luáces a partir de la traducción al español que hizo José Martí de este texto cuando vino a vivir a los Estados Unidos, pero si comparamos ambos podemos ver que, a pesar de que Lila utiliza imágenes animales para describir las acciones de los soldados, el traductor agrega giros lingüísticos que le imprimen aún más fuerza a la escena. Por ejemplo, De Luáces utiliza frases como "sinvergüenza infernal" (infernal scoundrel), demonios (“fiends") $(1871,4)$ y dice que estos actuaron "como tigres enloquecidos por la sangre de sus víctimas" ("maddened like tigers by the blood of their victims") (4). Sin embargo, Martí repite estos adjetivos, cambia la perspectiva de la locución, agrega signos de exclamación, y enfatiza la ironía ya que donde dice en el texto original: "It is said that it 
was carried off on the point a bayonet as a trophy" $(1871,4)$ Martí escribe: "Y cuando al día siguiente, consiguieron encontrar seis cadáveres,-faltaba en ellos la cabeza de una niña de cuatro años- ¡trofeo quizás de la heroicidad de aquellas hienas!-". Nótese, por tanto, como la frase impersonal "se dice que fue llevada [la cabeza] en la punta de la bayoneta como trofeo" se vuelve una locución exclamativa, llena de fuerza acusatoria.

Para resumir y concluir entonces, es importante prestar atención a los textos de la guerra producidos por mujeres. Ningún libro o artículo ha analizado hasta ahora la forma en que las mujeres, ya sean cubanas o norteamericanas, participan en el conflicto contando sus vivencias, criticando a las autoridades espańolas e insertándose ellas mismas en la Historia nacional. La ausencia de estos textos es de esperarse porque en la época no se suponía que las mujeres participaran de los debates políticos, que acompañaran a sus maridos en la guerra o incluso que fueran a la escuela. Solo se les exigía que cuidaran a sus hijos y a sus esposos, de modo que las mujeres que no eran de la clase alta o que no habían recibido una educación fuera de Cuba, no tenían acceso a la esfera pública a través de la letra, no formaban parte de la república de las letras en un país donde ellas eran doblemente marginadas, por el poder colonial español y por el sistema patriarcal. De ahí que los textos que hablan de su experiencia sean tan pocos.

En el caso de Cuba hasta ahora solamente se han encontrado los dos que he discutido en este ensayo en el que he subrayado las diferencias de clase que aparecen reflejadas, el uso de un lenguaje acusatorio, directo y emotivo para referirse la vida personal en el caso de Rodríguez, y los críme- 
Voces femeninas en la guerra de independencia de Cuba: Lila de Luáces y Eva Adán de Rodríguez

nes de los soldados españoles en el caso de Luáces. A diferencia entonces de los testimonios que hemos venido a conocer en el siglo XX, estas otras narraciones no fueron escritas por mujeres indígenas, iletradas o que pertenecían a la clase baja de la sociedad. No eran proletarias tampoco. Los textos escritos por mujeres que hablan de la guerra de Cuba provienen de mujeres que pertenecieron antes a la clase alta, que tenían esclavos y plantaciones, y una educación esmerada que les permitió de forma excepcional participar en el debate. No son tampoco autobiografías en el sentido clásico de la palabra porque en estas narraciones no se cuenta una vida, sino el pasaje o la experiencia de esa vida que es más importante. Eso sí, son narraciones abiertamente políticas que toman partido con los independentistas y por eso se convierten en memorias alternativas con las cuales fundar un nuevo discurso anticolonial y una nueva nación.

\section{Referencias BiblográficAs}

Assmann, Aleida. Cultural memory and western civilization. Cambridge: Cambridge University Press, 2011.

Barnet, Miguel. Biografía de un cimarrón. La Habana: Academia de Ciencias de Cuba, 1966.

Beverley, John. Testimonio: on the politics of truth. Minnesota: University of Minnesota Press, 2004.

Camacho, Jorge. Amos, siervos y revolucionarios: la literatura de las guerras de Cuba (1868-1898). Una perspectiva transatlántica. Madrid: Iberoamericana/Vervuert, 2018. 
De Luáces, Lila Waring. "Atrocities in Cuba. Narrative of a former resident within the insurgent lines. Inhuman treatment of Cubans by the Spanish authorities". In: The New York Tribune. 16 de December, 1871, 4.

El Moro Muza, "Céspedes inmoral y bígamo". 16/6/1870, 301.

El Moro Muza, "Los que hoy libertad proclaman". 21/11/1869, 64

Foucault, Michel. Language, Counter-Memory, Practice: Selected Essays and Interviews. Ed. Donald F. Bouchard. Ithaca: Cornell UP, 1977.

Loret de Mola, Melchor. Episodio de la Guerra de Cuba: El 6 de enero de 1871. Puerto Príncipe: Imprenta la Luz San Digo, 1893.

Martí, José. "Atrocidades en Cuba". In: Obras Completas. Edición crítica. Vol. 21. La Habana: Centro de Estudios Martianos, 2008, 436- 449.

Misch, Georg. History of Autobiography in Antiquity. New York: Routledge, 2014.

Perpiná, Antonio. El Camagüey, viajes pintorescos por el interior de Cuba y por sus costas. Barcelona: liberaría de J. A. Bastinos, 1889.

Rodríguez, Eva Adán. Hojas de Recuerdos. Prólogo Gonzalo Aróstegui y del Castillo. Epílogo de Miguel de Marcos. La Habana: Imprenta Molina y Cía, 1935.

Sierra Madero, Abel. Del otro lado del espejo: La sexualidad en la construcción de la nación cubana. La Habana: Casa de las Américas, 2006.

Smith, James Bruce. Politics \& Remembrance. Republican Themes in Machiavelli, Burke, and Tocqueville. Princeton: Princeton University Press, 1985. 